Acta Theriologica 43 (2): 185-193, 1998.

PL ISSN 0001-7051

\title{
Growth studies in Akodon dolores (Rodentia: Muridae) in captivity
}

\author{
Martha PIANTANIDA and Georgina E. BARRANTES*
}

\begin{abstract}
Piantanida M. and Barrantes G. E. 1998. Growth studies in Akodon dolores (Rodentia: Muridae) in captivity. Acta Theriologica 43: 185-193.

Growth processes in Akodon dolores Thomas, 1916 were studied by measuring morphological variables in a captive colony of 1500 specimens. Sex differences were not statistically significant. Most variables fitted to a sigmoid function and showed the same behaviour up to 3 months of age: an acceleration in growth up to the first month, followed by a deceleration up to the third month. Growth variables reached their asymptotic value after the fourth month of age. An exception was the lens weight which continually increased with age without reaching an asymptotic value. The instantaneous growth rates became less than unity at the third month of age, indicating that the maximal percentile growth should be before this stage. The latter was corroborated with the body weight increase and body length curves in which the inflexion point was observed at the 1-month stage. In A. dolores this stage is physiologically associated with puberty and in the present study was reached when the animals achieved $40 \%$ of their adult body weight. This study is the basis of an age distribution
\end{abstract} study of $A$. dolores with a biological foundation.

Museo Argentino de Ciencias Naturales "Bernardino Rivadavia”, Angel Gallardo 470, Casilla de Correo 220, (1405), Buenos Aires, Argentina (MP); Instituto de Neurociencia, Departamento de Ciencias Biológicas, Facultad de Ciencias Exactas y Naturales, Universidad de Buenos Aires, Pabellón II, $4^{\circ}$ piso, Ciudad Universitaria, (1428), Buenos Aires, Argentina; e-mail: mortells@ns2.retina.ar (GEB)

Key words: Akodon, growth studies, captivity

\section{Introduction}

In ecological studies attempting to investigate population dynamics, the determination of the age structure of a population and its variation among time has been problematic. Until recently, in most of the field work concerning various species of mammals from small rodents to large species such as foxes or monkeys, researchers have used several criteria to assess categories of relative ages (Lord 1959, Crespo 1971, Bothman et al. 1972, Jackson 1986, Voss et al. 1990, Varela et al. 1991, Percich and Hodara 1993).

In designing a model of age distribution, it is important to perform a detailed analysis of the relationships between the growth of several morphological variables in animals of known age. Subsequently, it is necessary to establish which of the

\footnotetext{
* To whom correspondence should be sent.
} 
morphological variables best correlate with animal age (Pruitt et al. 1979). The estimators most frequently used have been body weight, molar abrasion (in the case of rodents), closing of bony structures in skull and big bones and lens weight. Lens weight is the morphological parameter usually considered to correlate best with growth and therefore with the animal age (Lord 1959, Hagen et al. 1980, Rusch et al. 1982). However, in most of the field studies it is impossible to measure it.

In the present work, the growth characteristics of several variables from birth up to the maximal age of a captive colony of the murid Akodon dolores Thomas, 1916 are presented. This species is of great importance within the murid communities in Córdoba Province of Argentina, due to its large population size (Piantanida 1987, Varela and Polop 1991). Therefore, the present study constitutes the basis to perform an age distribution study of $A$. dolores with a biological foundation.

\section{Material and methods}

The A. dolores colony was started with specimens from Laguna Larga, Córdoba province, Argentina $\left(63^{\circ} 48^{\prime} \mathrm{W}, 31^{\circ} 46^{\prime} \mathrm{S}\right.$. The colony was maintained and manipulated as previously described by Piantanida (1987). More than 1500 animals were raised in captivity and a sample of 20 individuals was used for every measurement.

Animal growth was followed until natural death. However, some animals were killed at different ages to obtain internal morphology data. In this case (and for naturally dead animals as well), skull, large bones, lens and genital apparatus were preserved; skins were extended and prepared as described by Piantanida (1987).

External body measurements were obtained with a Vernier like caliber. New-born animals were weighted with a $\mathrm{mg}$ precision balance. The bones from 1 to 30 days old animals were prepared following the standard procedure of transparentization with alizarin. Measurements were carried out on transparentized material. According to the technique described by Lord (1959), lens were dried in a hood until constant weight. Skin colours were analysed following Villalobos and Dominguez (1947). To perform statistical analysis, measurements were carried out every 7 days within the first month Subsequently, animals were measured every 30 days. However, after the eleventh month of age, data measurements were pooled within intervals of 5 months of absolute age since at this stage the data were incomplete. The latter procedure was justified because at this stage the growth curve has already reached the plateau. Curve fitting was based on Brody's (1945) proposal and the quantitative analysis of the growth was followed as described by Kingsley (1979).

\section{Results}

Growth variables fitted to a sigmoid (logistic) function with a correlation coefficient $(r)$ near unity and reached the asymptotic value after the fourth month of age (Figs 1-3). An exception was the lens weight which increased continually with age without reaching an asymptotic value (Fig. 4).

Body weight was one of the measurements which seemed to be most affected by the environmental conditions and the activities displayed by the animals. The 
a

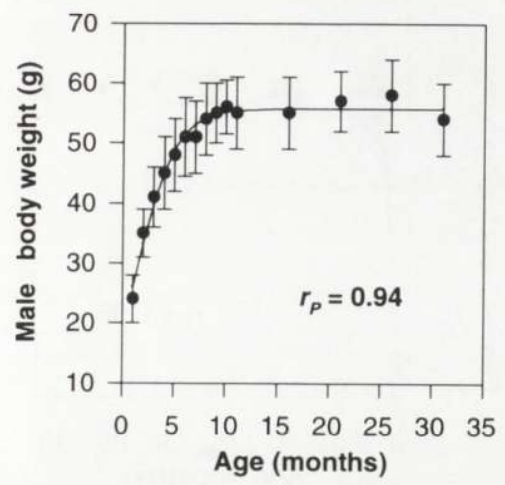

C

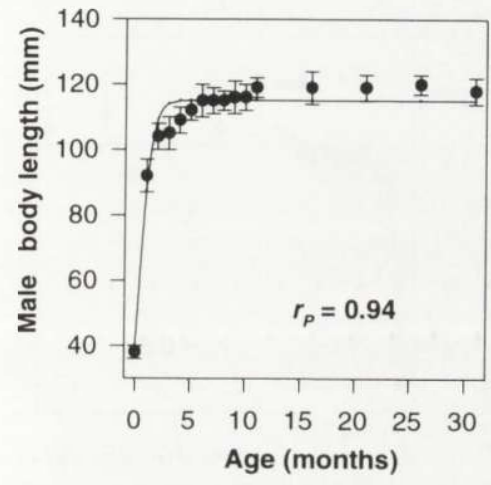

b

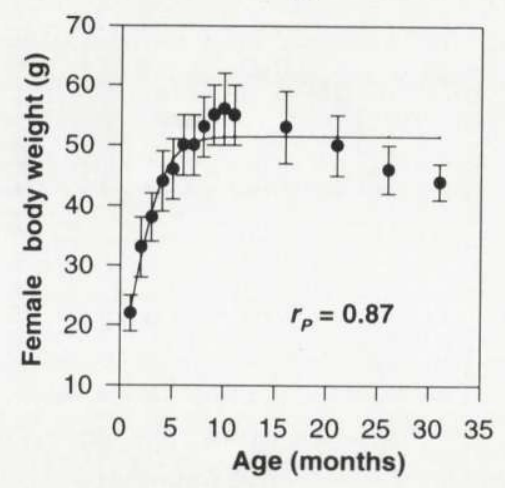

d

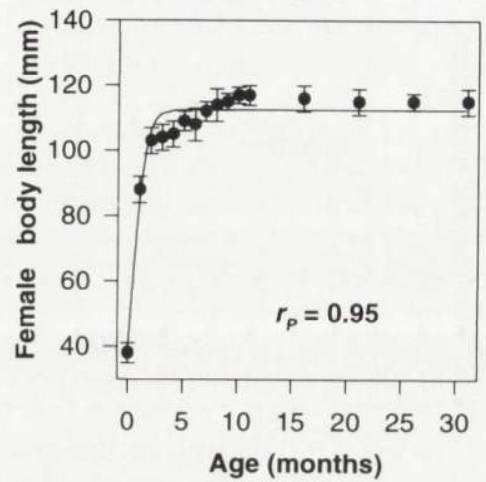

Fig. 1. Body weight and length growth (mean \pm SE) versus age in Akodon dolores ( $n=20$ for each dot). Data were fitted to a sigmoid function $Y_{(x)}=a /[1+(b \times \exp (-c X)]$, where $a$ represents the values at where there is no more further changes (asymptotic value), $b$ the value for " $a-Y$ " at time $0, c$ the potential growth rate, and $X$ the time at which data were determined.

variability between samples was very large and this is reflected in the large dispersion values obtained (Fig. 1a and b). After five months of age males and females reached the asymptotic value. However, females were less robust than males (Fig. 1b). The same trend appeared in the other variables measured. In particular, body length, which showed the maximum growth values within 4-5 months (Fig. 1c and d). Tail growth analyses were avoided since they suffered modifications mainly due to manipulations and fights. Given that feet and ear growth rates were very fast and reached a maximum in the second month, these variables were not included in the analysis. Skull growth and bizygomatic width showed the same characteristics to those of the external body variables, reaching maximum values within 4-5 months (Fig. 2). As shown in Fig. 3a and b, large bones such as the humerus and femur, reached maximum growth values within 
a

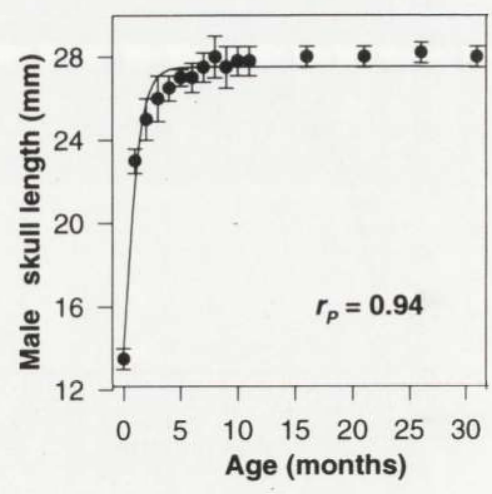

C

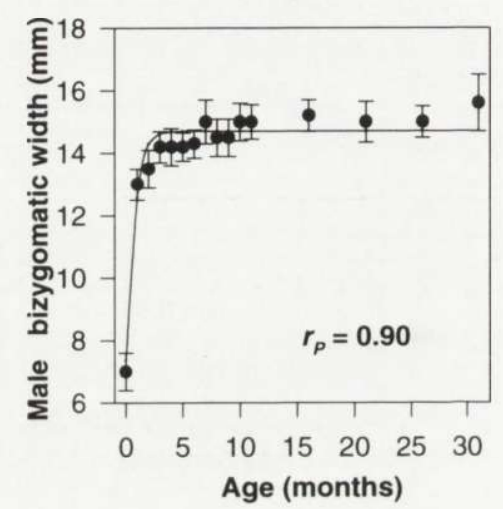

b

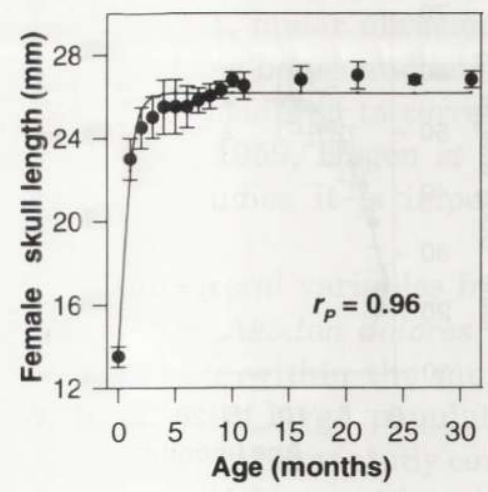

d

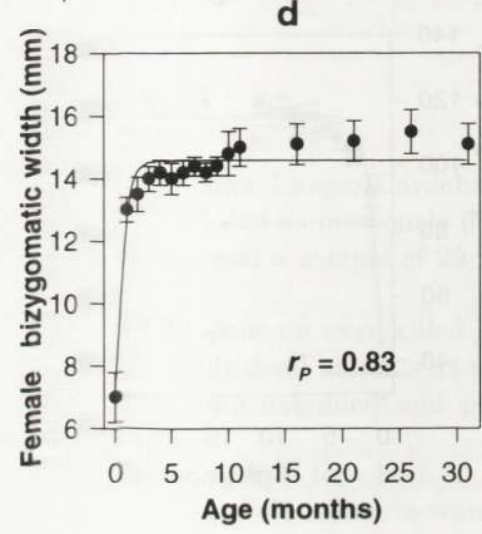

Fig. 2. Skull length and bizygomatic width growth (mean \pm SE) versus age in Akodon dolores $(n=20$ for each dot). Data were fitted to a sigmoid function $Y_{(x)}=a /[1+(b \times \exp (-c X)]$. See Fig. 1 for explanations.

4 months. In addition, these bones thickened in diameter with time, probably due to calcium accumulation.

Particular attention is deserved by the only variable that showed continuous growth through the animal's life: lens weight. Its growth accelerated during the first months (similarly to the other variables) and then decelerated but without stopping. Lens weight was related to age and fitted to a sigmoid function (Fig. 4).

The degree of closing of the distal and proximal cartilaginous sutures in femur and humerus was also analysed. Four classes or degrees of ossification could be distinguished: (1) the epiphysis totally loose, (2) the sutures open but difficult to separate, (3) the ossification process more advanced but with the separation still evident, (4) the epiphysial suture totally ossified although the ossification line remained visible. This case is typical of older animals. 
a

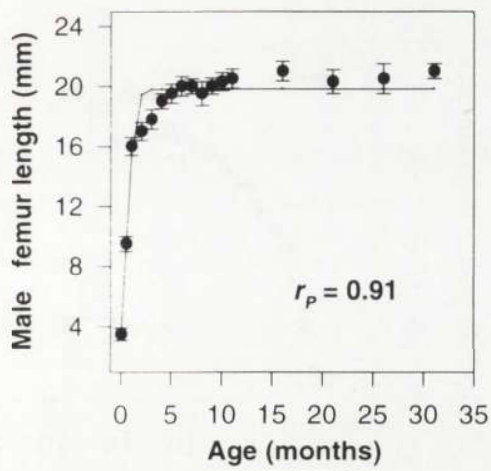

c

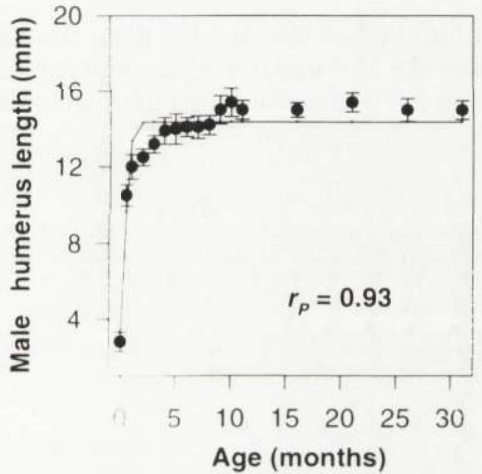

b

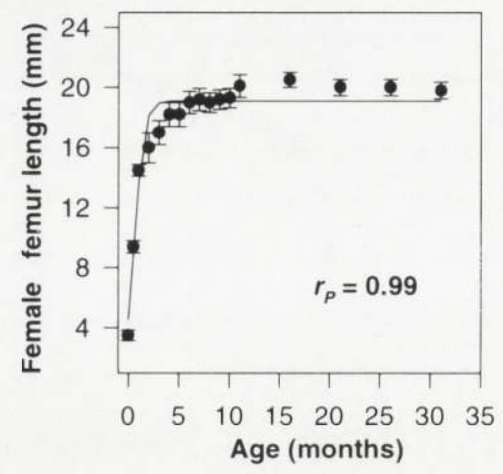

d

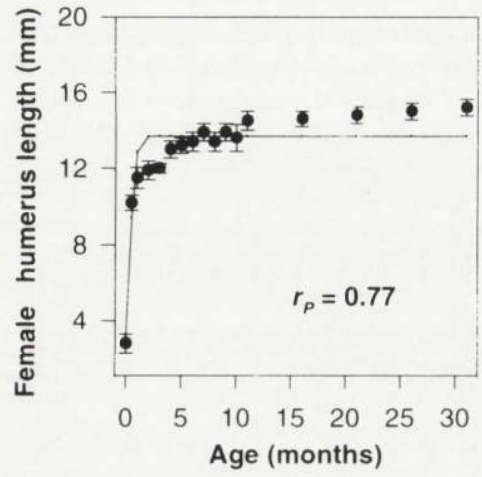

Fig. 3. Femur and humerus length growth (mean \pm SE) versus age in Akodon dolores ( $n=20$ for each dot). Data were fitted to a sigmoid function $Y_{(x)}=a /[1+(b \times \exp (-c X)]$. See Fig. 1 for explanations

The following ossification sequence of the skull sutures were observed: (1) condyle-basioccipital, (2) exoccipital-supraoccipital, (3) presphenoid-basisphenoid, (4) basisphenoid-basioccipital, (5) interparietal, (6) parietal-frontal.

The skull sutures listed above remained open until the second month of life. The condyle-basioccipital suture was ossified by the age of 3 months. Animals did not undergo any further changes until the sixth month of age. Between the sixth and tenth months of age the exoccipital-supraoccipital, presphenoid-basisphenoid, basisphenoid-basioccipital and dorsal skull sutures became successively ossified. In 8 to 9 months old animals it was still possible to observe open interparietal and parietal-frontal sutures; thereafter most of the cranial sutures were completely ossified.

As a complement to the preceding analysis, the colour variation, that the skin undergoes during development, was also studied. Animals between 1 and 2 months old showed a light-brown back with a ventral region almost yellow. Mature animal 
a

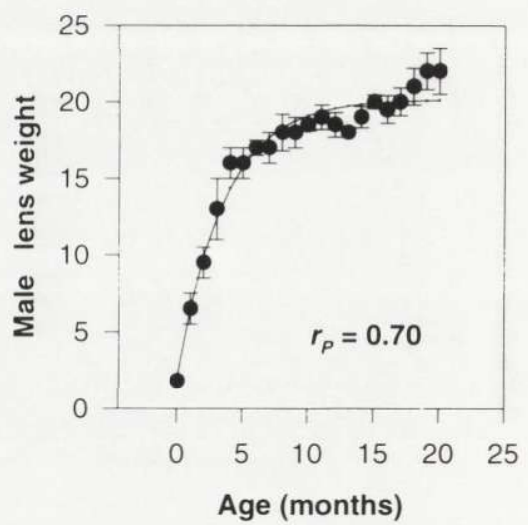

b

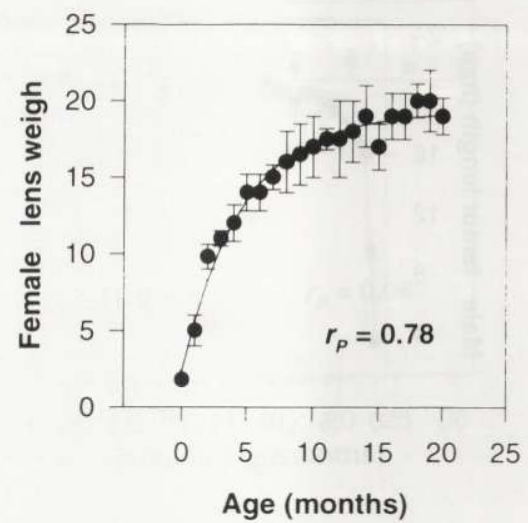

Fig. 4. Lens weight (mean $\pm \mathrm{SE}$ ) versus age in Akodon dolores ( $n=20$ for each dot). Data were fitted to the equation $Y_{(x)}=a-[b \times \exp (-c X)]$, where $a$ represents the theoretical asymptotic value, $b$ the value for " $a-Y$ " at time $0, c$ the potential growth rate, and $X$ the time at which data were determined.
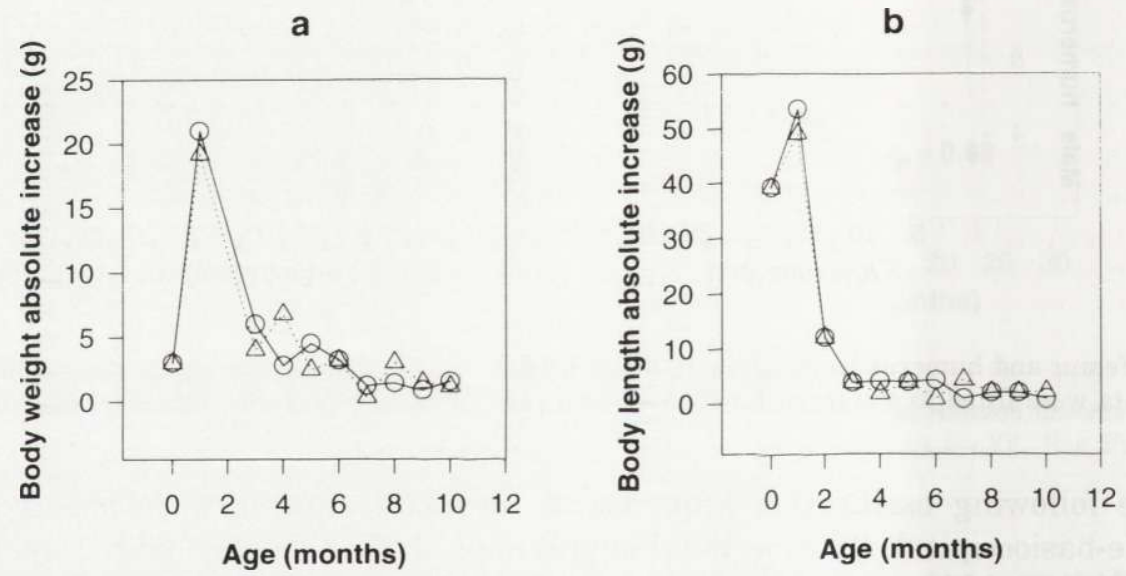

Fig. 5. Body weight and length absolute increase versus age in Akodon dolores. Data were calculated with the equation $Y_{(t)}=\left(\ln X_{2}-\ln X_{1}\right) /\left(t_{2}-t_{1}\right) \times 100$, where $X_{2}$ and $X_{1}$ represent mean values at times $t_{2}$ and $t_{1}$, respectively. Every point correspond to the mean value of 20 determinations. Continuous lines and circles correspond to results for males, dotted lines and triangles - for females.

backs were brown, where the sides were rather lighter and the ventral region was grey with few yellow hairs. The definitive coloration was reached at fourth month.

Table 1 shows the relative percentile rate of growth obtained for each variable. The instantaneous growth rates became less than unity by the third month of age, indicating that the maximal percentile growth should be before this stage. This was corroborated by calculating the monthly absolute increase of the body weight 
Table 1. Instantaneous percentile rate of growth for the variables studied in Akodon dolores. Data are total mean values for 20 females +20 males.

\begin{tabular}{rccccccc}
\hline $\begin{array}{l}\text { Age } \\
\text { (months) }\end{array}$ & $\begin{array}{c}\text { Body } \\
\text { weight }\end{array}$ & $\begin{array}{c}\text { Body } \\
\text { length }\end{array}$ & $\begin{array}{c}\text { Skull } \\
\text { length }\end{array}$ & $\begin{array}{c}\text { Bizggomatic } \\
\text { width }\end{array}$ & $\begin{array}{c}\text { Femur } \\
\text { length }\end{array}$ & $\begin{array}{c}\text { Humerus } \\
\text { length }\end{array}$ & $\begin{array}{c}\text { Lens } \\
\text { weight }\end{array}$ \\
\hline 1 & 6.25 & 2.73 & 1.62 & 2.06 & 4.59 & 4.79 & 4.15 \\
2 & 1.33 & 0.40 & 0.24 & 0.20 & 0.26 & 0.15 & 1.64 \\
3 & 0.41 & 0.10 & 0.10 & 0.13 & 0.20 & 0.19 & 0.71 \\
4 & 0.36 & 0.08 & 0.06 & 0.05 & 0.22 & 0.17 & 0.46 \\
5 & 0.24 & 0.09 & 0.03 & 0.08 & 0.06 & 0.06 & 0.31 \\
6 & 0.24 & 0.05 & 0.00 & 0.08 & 0.07 & 0.05 & 0.10 \\
7 & 0.03 & 0.06 & 0.05 & 0.11 & 0.03 & 0.07 & 0.13 \\
8 & 0.06 & 0.05 & 0.06 & 0.04 & 0.05 & 0.06 & 0.20 \\
9 & 0.06 & 0.05 & 0.07 & 0.07 & 0.03 & 0.10 & 0.07 \\
10 & 0.06 & 0.03 & 0.06 & 0.08 & 0.06 & 0.09 & 0.13 \\
\hline
\end{tabular}

and body length. The inflexion point was observed around the age of 1 month (Fig. 5 ). It is important to note here that absolute does not mean total in the standard mammal measurement sense since in most of the cases tails were mutilated. Therefore body length measurements did not include tail length.

\section{Discussion and conclusions}

Following Brody's (1945) definition of growth, it was possible to establish growth patterns by fitting some equations to the points generated from the growth data (Zullinger et al. 1984). As stated in the Results, the growth pattern of the majority of the morphological variables could be fitted to a sigmoid function in accordance with growth studies in several other mammalian species (Laird et al. 1965, Rice and Wolman 1971, Kingsley 1979, Piantanida and Nani 1993). However, an exception was the lens weight $(r>0.7)$.

With respect to the weight values, the asymptote was reached very slowly and in older animals the points dropped. The decrease in body weight was more evident in females. These results could be attributed to an overestimation of the body weight in the intermediate age classes due to pregnancy.

All the growth variables showed the same behaviour up to the third month of age. The trend was: (1) an acceleration from birth, up to the first month of age; (2) a deceleration up to the third month where every variable had its particular behaviour; (3) from the fifth month of age, growth variables reached the asymptotic value.

The inflexion point in Fig. 5 was reached at the stage of 1 month when the animals achieved $40 \%$ of the adult body weight. As it has been observed in most mammals (Crespo et al. 1970, de Villafañe 1981a, b), there is an equivalent point 
in the geometrical and physiological age. In A. dolores this stage is physiologically associated with puberty (Piantanida 1987) since the sexual organs are completely formed and mature at the stage of 1 month. Considering puberty as the transition between the pups and the adult developmental stages and, in addition, as the stage in which the sexual maturity is reached, $A$. dolores consequently reached puberty when the animals achieved $40 \%$ of the adult body weight.

The only morphological variable that showed a peculiar behaviour was the lens weight. This increased continually with age without reaching an asymptotic value. This might explain why the growth curve did not fit the logistic function as in the other cases. Therefore, this parameter can be considered a good age estimator and for this reason it could be used as the pillar for the construction of an age pattern.

In conclusion, the present analysis allowed the mathematical description of the growth of $A$. dolores on the basis of several body measurements and therefore constitutes the basis of an age distribution study of this species with a biological meaning.

Acknowledgments: The Departamento of Cálculo FCEyN, Universidad de Buenos Aires is acknowledged for the statistical analysis. Dr M. O. Ortells, Dr J. Crespo and Lic. O. Vaccaro are acknowledged for reading the manuscript. This work was supported by CONICET, Argentina.

\section{References}

Bothman J., Teer J. G. and Gates C. E. 1972. Growth and age determination of the cottontail in South Texas. Journal of Wildlife Management 36: 1209-1226.

Brody S. 1945. Bioenergetics and growth. Reinholt Publishers Co., New York: 1-1023.

Crespo J. A. 1971. Ecología del zorro gris (Dusicyon gymnocercus antiquus, Ameguino) en la provincia de La Pampa. Revista del Museo Argentino de Ciencias Naturales, Ecología 1: 1-55.

Crespo J., Sabatini M., Piantanida M. and de Villafañe G. 1970. Estudios ecológicos sobre roedores silvestres. Ministerio de Bienestar Social, Buenos Aires: 3-34.

de Villafañe G. 1981a. Reproducción y crecimiento de Akodon azarae azarae (Fhicher 1982). Historia Natural 1: 193-204.

de Villafañe G. 1981b. Reproducción y crecimiento de Calomys musculinus murillus (Thomas 1916). Historia Natural 1: 237-256.

Hagen A., Stenseth N. C., Ostbye E. and Skan J. 1980. The eye lens as an age indicator in the root vole. Acta Theriologica 25: 39-50.

Jackson J. 1986. Determinación de la edad en la viscacha (Lagostomus maximus) en base al peso del cristalino. Vida Silvestre Neotropical 1: 41-44.

Kingsley M. C. S. 1979. Fitting the von Bertalanffy growth equation to polar bear age-weight data. Canadian Journal Zoology 57: 1020-1025.

Laird A. K., Tyler S. A. and Barton A. D. 1965. Dynamics of normal growth. Growth 29: 233-248.

Lord R. D. 1959. The lens as an indicator of age in the grey fox. Journal of Wildlife Management 23: $358-360$.

Percich R. E. and Hodara V. L. 1993. Crecimiento en laboratorio de roedores cricétidos: variables craneanas y peso de cristalino de (Calomys callidus). Physis 48: 7-14.

Piantanida M. J. 1987. Distintos aspectos de la reproducción en la naturaleza y en cautiverio del roedor cricétido (Akodon dolores) (Thomas, 1916). Physis 45: 47-58. 
Piantanida M. J. and Nani N. 1993. Reproducción y crecimiento de (Bolomys temchuki) (Massoia, 1980) en cautiverio (Rodentia Cricetidae). Revista del Museo Argentino de Ciencias Naturales, Ecología 4: 39-51.

Pruitt K. M., De Muth R. E. and Tuner M. E. 1979. Practical application of generic growth theory and the significance of the growth curve parameters. Growth 43: 19-35.

Rice D. W. and Wolman A. A. 1971. The life history and ecology of the grey whale (Eschrichtius robustus). Special Publication, The American Society of Mammalogists 3: 1-142.

Rusch D. A., Reeder W. G. and Rusch D. H. 1982. Eye lens, testes and body weight trends in Alberta red squirrels. Journal of Wildlife Management 46: 1010-1017.

Varela H. H. and Polop J. J. 1991. Variación morfométrica por edad y sexo en Akodon dolores (Rodentia Cricetidae) por caracters morfométricos a través de técnicas de análisis multivariado. Revista de la Universitad de Río Cuarto 11: 51-61.

Varela H. H., Provenzal M. C. and Polop J. J. 1991. Determinación de la edad en (Akodon dolores) (Rodentia Cricetidae) por caracteres morfométricos a través de técnicas de análisis multivariado. Revista de la Universidad de Río Cuarto 11: 123-131.

Villalobos C. J. and Dominguez J. 1947. Atlas de los colores. El Ateneo, Buenos Aires: 1-71.

Voss R. S., Marcus L. F. and Escalante P. P. 1990. Morphological evolution in muroid rodents I. Conservative patterns of craniometric covariance and their ontogenetic basis in the neotropical genus Zygodontomys. Evolution 44: 1568-1587.

Zullinger E. M., Ricklefs R. E., Redford K. H. and Mace G. M. 1984. Fitting sigmoidal equations to mammalian growth curves. Journal of Mammalogy 65: 607-635.

Received 28 October 1996, accepted 4 September 1997. 